\title{
Guía de manejo obstétrico y del recién nacido en madre aloinmunizada
}

Guidelines for the obstetric management of an alloimmune mother and her newborn Guia de manejo obstétrico e neonatal em mães aloimunizadas

Gabriela Rivas ${ }^{1}$, Virginia Marcalain ${ }^{1}$, Juan Recouso², Valentina Silveira³ ${ }^{3}$, Jimena Bentos ${ }^{1}$, Valeria Alonso², Valeria Correa², Mariana Sauleda², Florencia Garat4, Luis Miguel Gómez", Marcelo De Agostini, Cristina Cordano ${ }^{4}$, Grazzia Rey², Ismael Rodríguez¹, Fernanda Blasina ${ }^{3}$

\section{Resumen}

La aloinmunización es una respuesta biológica frente a la exposición de antígenos no propios. La gestación, las transfusiones de hemocomponentes, los trasplantes de órganos sólidos y células hematopoyéticas, así como el consumo de drogas intravenosas exponen a las pacientes al desarrollo de aloanticuerpos antieritrocitarios. El hallazgo de los mismos debe cumplir con las instancias diagnósticas para identificar la probabilidad de estar asociados a enfermedad hemolítica feto neonatal (EHFN) y su oportuna derivación a policlínica de alto riesgo obstétrico (ARO) para su correcto seguimiento. Es fundamental que sean los laboratorios de inmunohematología de los servicios de hemoterapia y medicina transfusional los encargados de los estudios diagnósticos de aloinmunización eritrocitaria(1). En este sentido hemos elaborado esta guía con el objetivo de protocolizar de manera multidisciplinaria el manejo de las embarazadas aloinmunizadas y sus recién nacidos.

Palabras clave: Isoinmunización

Enfermedad hemolítica del recién nacido

Enfermedad hemolítica del feto

Flujometría por láser-Doppler

Anemia neonatal

Embarazo

Aloinmunización

Immunoprofilaxis anti D

Key words: Isoimmunization

Hemolytic disease of the newborn

Hemolytic disease of the fetus

Laser-Doppler flowmetry

Anemia, neonatal

Pregnancy

Alloimmunization

Anti D immunoprophylaxis

1. Cátedra y Departamento de Hemoterapia y Medicina Transfusional. Prof. Dr. Ismael Rodríguez, Facultad de Medicina, Hospital de Clínicas, UDELAR.

2. Clínica Ginecológica B Prof. Dr. Washington Lauría Morgades, Facultad de Medicina, Hospital de Clínicas, UDELAR.

3. Departamento de Neonatología, Facultad de Medicina, Hospital de Clínicas, UDELAR.

4. Unidad de Ecografía Gineco-Obstétrica y Medicina Fetal, Clínica Ginecotocológica B, Facultad de Medicina, Hospital de Clínicas, UDELAR.

Hospital de Clínicas, Montevideo, Uruguay.

Correspondencia: Dra. Gabriela Rivas Alén. Correo electrónico: grivas@hc.edu.uy

Recibido: 4/2/2021

Aprobado: 14/7/2021

Attribution-NonCommercial 4.0 International (CC BY-NC 4.0) 


\section{Objetivos}

La guía de manejo obstétrico y recién nacido en madre con riesgo de aloinmunización tiene la finalidad de establecer un referente nacional para orientar la toma de decisiones clínicas basadas en recomendaciones sustentadas en la mejor evidencia disponible.

Esta guía pone a disposición del personal del primer, segundo y tercer nivel de atención las recomendaciones basadas en la mejor evidencia disponible con la intención de estandarizar las acciones nacionales llevando a la intervención en:

1. Identificar gestantes con aloinmunización que requiera seguimiento en policlínicas de alto riesgo obstétrico.

2. Identificar factores de riesgo para la enfermedad hemolítica en el recién nacido.

3. Realizar diagnóstico temprano del recién nacido con enfermedad hemolítica e Iniciar tratamiento oportuno al recién nacido con enfermedad hemolítica.

4. Identificar aquellas gestantes RH Negativos que requieren la administración de inmunoprofilaxis anti D

5. Identificar aquellas gestantes que puedan requerir estudios de biología molecular para genotipo del gen RH.

\section{Metodología}

Para el desarrollo de esta guía se realizó una búsqueda de documentos bibliográficos comprendidos en el período 2000-2020. Las bases de datos utilizadas fueron las principales disponibles en internet: PubMed, biblioteca Cochrane, Portal Timbó (actualmente Timbó Foco), así como aquellas de ámbitos nacionales como son las publicaciones del MSP de Uruguay.

Se utilizaron descriptores comprendidos dentro de tres bloques: abordaje obstétrico, abordaje inmunohematológico y por último abordaje neonatal. Las palabras claves utilizadas para la búsqueda dentro de los tres bloques mencionados fueron: aloinmunización materna durante el embarazo (Maternal alloimmunization in pregnancy), anemia fetal (fetal anemia) enfermedad hemolítica del feto y de recién nacido (hemolytic disease of the fetus and the newborn), immunoprophylaxis anti D (anti D immunoprophylaxis), flujometría Doppler fetal (Fetal Doppler Flowmetry).

Los tres bloques de búsqueda anteriormente mencionados fueron utilizados para la organización del material seleccionado.

Criterios de inclusión: estudios experimentales, ensayos clínicos, guías nacionales de manejo publicados en el periodo 2000- 2020 que cumplieran con criterios de factibilidad y validez aceptables por el grupo de trabajo.
Fueron encontrados 1088 resultados en el bloque obstétrico, 215 en el bloque inmunológico y 313 en el bloque neonatal. De éstos se accedieron y seleccionaron las guías, meta análisis y revisiones.

\section{Introducción}

La aloinmunización en la gestación ha descendido francamente desde la introducción de la inmunoglobulina anti-D en la década de 1070, sin embargo sigue siendo la principal causa de anemia fetal. Aproximadamente en $1 \%$ de las mujeres embarazadas se encuentran aloanticuerpos clínicamente significativos ${ }^{(1)}$. Algunos aloanticuerpos están asociados con patología fetal y neonatal significativa como anemia, hiperbilirrubinemia o muerte perinatal. La aloinmunización por anti $\mathrm{D}$ es la causa más frecuente y más grave de aloinmunización sintomática, constituyendo la mayoría de los casos que requieren tratamiento intraútero. Con el resto de los aloanticuerpos puede observarse anemia fetal grave en la enfermedad hemolítica feto neonatal por anti c y Kell, raramente por el anti E y excepcionalmente con el resto.

La profilaxis para la aloinmunización solo es posible para el antígeno Rh D. Se basa en la administración de inmunoglobulina anti D que eliminará de la circulación materna los glóbulos rojos $\mathrm{Rh} \mathrm{D}$ positivo de origen fetal. La administración debe realizarse frente a cada episodio potencialmente sensibilizante, tras el parto de un recién nacido (RN) Rh D positivo y de forma sistemática a las 28 semanas de gestación en mujeres $\mathrm{Rh} \mathrm{D}$ negativas no inmunizadas para el antígeno D.

Dividiremos este documento en tres apartados; el manejo obstétrico, inmunohematológico y neonatal.

\section{Abordaje obstétrico}

Ante el diagnóstico de embarazo debe indicarse la evaluación inmunohematológica de toda paciente en el primer control de embarazo que debe incluir, independientemente de estudios realizados en embarazos previos: determinación de grupo sanguíneo en sistema $\mathrm{ABO}$ y $\mathrm{Rh}(\mathrm{D})$ y la investigación de anticuerpos irregulares.

Se deberá suministrar información sobre la inmunización anti $\mathrm{D}$, detección precoz, seguimiento y prevención.

Si la mujer es Rh D negativa y no está inmunizada contra el antígeno D se deberá realizar seguimiento inmunohematológico por parte del servicio de Medicina Transfusional, de acuerdo a las técnicas disponibles en cada centro.

La eficacia de la inmunoprofilaxis se basa en una dosis adecuada de anti D y en la inyección de inmunoglobulinas dentro de las $72 \mathrm{~h}$ posteriores a un episodio potencialmente inmunizante ${ }^{(2)}$. 


\section{Situaciones de inmunización}

Alrededor del 25\% de las inmunizaciones anti D se producen tras una hemorragia fetomaterna sin factores de riesgo identificables, sobre todo en el tercer trimestre. Pueden, por lo tanto, escapar a una prevención dirigida, ya que se produce el paso "espontáneo" de hematíes fetales a la circulación materna en $4 \%$ de los casos en el primer trimestre, en el $12 \%$ en el segundo y en el $45 \%$ en el tercero ${ }^{(3)}$. El 75\% restante ocurren en determinadas situaciones de riesgo identificables:

\section{Primer trimestre (riesgo moderado)}

- Aborto espontáneo o amenaza de aborto, incluyendo la interrupción voluntaria del embarazo (independiente del tratamiento empleado).

- Embarazo molar (si es parcial).

- Embarazo extrauterino (ectópico).

- Intervenciones: coriocentesis, amniocentesis, reducción embrionaria.

- Traumatismo abdominal.

El hallazgo de hematoma subcoriónico en la ecografía sin traducción clínica no sería indicación de inmunoprofilaxis.

Durante el primer trimestre no existe un límite inferior para llevar a cabo la prevención. Una inyección intramuscular o intravenosa única de 120 microgramos de inmunoglobulina anti D se justifica en todos los casos enumerados.

\section{Segundo y tercer trimestre (riesgo importante)}

- Interrupción médica del embarazo.

- Aborto espontáneo tardío.

- Metrorragias de la segunda mitad del embarazo.

- Muerte fetal intrauterina.

- Versión mediante maniobras externas.

- Traumatismo abdominal o pélvico.

- Intervención terapéutica intraútero.

- Cirugía abdominal o pélvica.

- Extracción ovular (amniocentesis, cordocentesis o placentocentesis).

- Parto, independientemente de la vía de finalización.

Durante el segundo y el tercer trimestre se debe administrar una dosis intravenosa de 120 microgramos o intramuscular de 300 microgramos a todas las mujeres $\mathrm{RhD}$ negativas a partir de las 28 semanas y hasta las 32 semanas de gestación inclusive, según pauta ministerial vigente $^{(4)}$.

En caso de confirmarse fenotipo del RN Rh D positivo, deberá administrarse inmunoglobulina anti $\mathrm{D}$ a la puérpera a una dosis de 120 microgramos intravenosa o 300 microgramos intramuscular en las primeras $72 \mathrm{~h} . \mathrm{Si}$ existiera omisión en este plazo, existe efectividad parcial hasta los 13 días, algunos expertos la recomiendan hasta los 28 días $^{(5)}$.

En caso de procedimiento de esterilización tubaria postparto, el Colegio Americano de Ginecología recomienda la inmunoprofilaxis debido al riesgo de falla del método y/o por fertilización in vitro posterior y la complicación de la terapia transfusional en caso de producirse la aloinmunización ${ }^{(6)}$.

\section{Diagnóstico de anemia fetal}

La anemia fetal puede diagnosticarse en el contexto de una aloinmunización conocida y con riesgo identificado de anemia, o más raramente pero desgraciadamente como hallazgo imagenológico en el seguimiento de una gestación (forma grave de presentación).

Valor de la ecografía y el Doppler fetoplacentario en el diagnóstico de anemia fetal

La concentración de hemoglobina fetal varía a lo largo de la gestación. La anemia fetal es un fenómeno multicausal, definido como aquel valor de hemoglobina fetal por debajo de 2 desvíos estándar (DE) de la media. Entre 2 y 4 DE se considera anemia leve, entre 4 y 6 de moderada y más de $6 \mathrm{DE}$ se considera anemia severa ${ }^{(7)}$.

La medición de la velocidad máxima del flujo sanguíneo en la arteria cerebral media (VSM-ACM) como predictor de riesgo de anemia fetal ha desplazado la amniocentesis con estudio espectrofotométrico del líquido amniótico, lo que ha disminuido en $70 \%$ la necesidad de procedimientos invasivos ${ }^{(8)}$.

Independientemente de la etiología, el riesgo de presentar anemia fetal puede ser detectado por ecografía Doppler sobre la base de un aumento de la velocidad máxima del flujo sanguíneo sistólico (VSM) en la ACM. Un valor de VSM-ACM mayor de 1,5 MoM se utiliza como prueba de screening para identificar un feto con anemia moderada o severa. En el 2000, Mari y colaboradores reportaron una sensibilidad de la VSM-ACM de $100 \%$ para la anemia moderada y severa, con $88 \%$ de especificidad y una tasa de falsos positivos de $12 \%{ }^{(9)}$. Sin embargo, en 2019 Borrell y colaboradores reportaron en un metaanálisis una sensibilidad de $86 \%$ y una especificidad de $71 \%$, con una tasa de falsos positivos de $29 \%$, en fetos sin transfusiones previas ${ }^{(10)}$.

La medición de la VSM-ACM mediante el estudio Doppler es el método principal de control y seguimiento en las pacientes aloinmunizadas catalogadas como de riesgo para EHFN.

Las pacientes se clasifican de alto o bajo riesgo según sus antecedentes perinatales y evolución de gestaciones previas, tipo de anticuerpo presente y titulación en algunos grupos de trabajo, sin ser éste en sí mismo un 


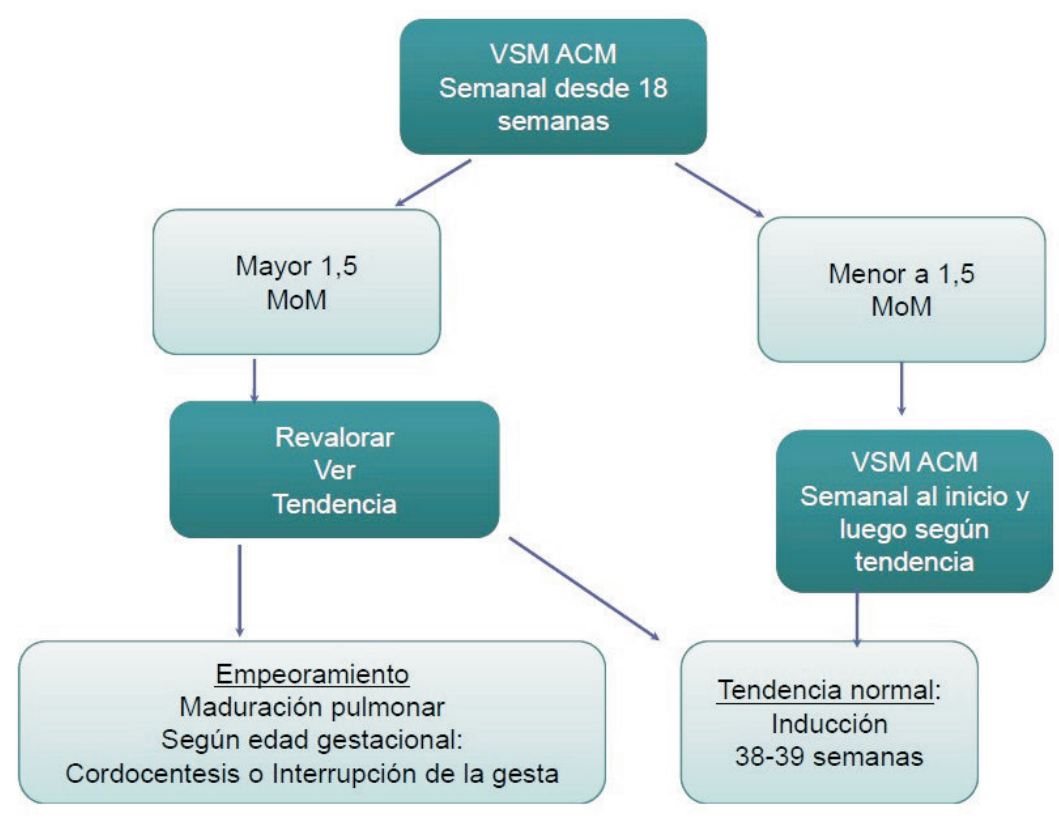

Figura 1. Tomado de Mari G. Middle cerebral artery peak systolic velocity for the diagnosis of fetal anemia: the untold story. Ultrasound Obstet Gynecol. 2005;25:323-330.

valor absoluto y definitivo a la hora de la toma de decisiones.

- Las pacientes de bajo riesgo podrán ser valoradas mediante estudio Doppler mensualmente o bimensualmente ${ }^{(7)}$.

- Las pacientes de alto riesgo se evaluarán desde la semana 18 como se explica a continuación.

\section{Seguimiento con Doppler en las pacientes de alto riesgo}

Se inicia en forma semanal (por lo menos las primeras tres semanas), luego se planifican los siguientes controles según la extrapolación de los valores obtenidos a la curva que se muestra en la figura 1.

En vez de considerar un valor aislado, se recomiendan las mediciones consecutivas para valorar la tendencia del resultado obtenido. De esta manera se disminuyen los falsos positivos. Los fetos que desarrollarán anemia moderada o severa tienen un incremento de la VSM-ACM mayor y más rápido que aquellos que tendrán niveles de hemoglobina normal o anemia leve. De este modo, viendo la pendiente de la curva se podrá detectar con anticipación a aquellos fetos que están en mayor riesgo pero que todavía presentan valores normales en la VSM-ACM.

Con este fundamento, si la curva trazada con los valores de la paciente se encuentra hacia la derecha de la curva que corresponde a la anemia moderada, se pueden espaciar los controles a cada 14 días. Por el contrario, si la curva presenta una pendiente elevada y se encuentra a la izquierda de la curva de la anemia moderada, se continúa con los controles semanales ${ }^{(11)}$.

Siguiendo la misma metodología de estudio, si el feto tiene una curva normal o con anemia leve, luego de las 35 semanas la medición de la VSM-ACM podría generar intervenciones innecesarias por lo que el valor debe ser interpretado con cautela.

Si los valores obtenidos son mayores a 1,5 MoM en embarazos menores de 35 semanas y 6 días, se deberá repetir el estudio en 24 a $48 \mathrm{~h}$, para disminuir los falsos positivos (menos de 5\%). En caso de empeorarse la tendencia y en función de la edad gestacional, se optará por realizar una cordocentesis diagnóstica y eventualmente terapéutica o finalización de la gestación (figura 2) ${ }^{(11)}$.

\section{Cordocentesis}

Consiste en la punción del cordón umbilical mediante una aguja introducida por vía transabdominal, bajo visión ecográfica. Permite el acceso a la circulación fetal y la obtención de una muestra de sangre fetal pura para tipificación precisa y confiable del grupo sanguíneo fetal, monitoreo del nivel de hemoglobina y eventual transfusión sanguínea si la misma se encuentra por debajo de 4 desvíos estándar para la edad gestacional.

De acuerdo centros de referencia internacionales está indicada hasta las 35 semanas más 6 días ante la eleva- 


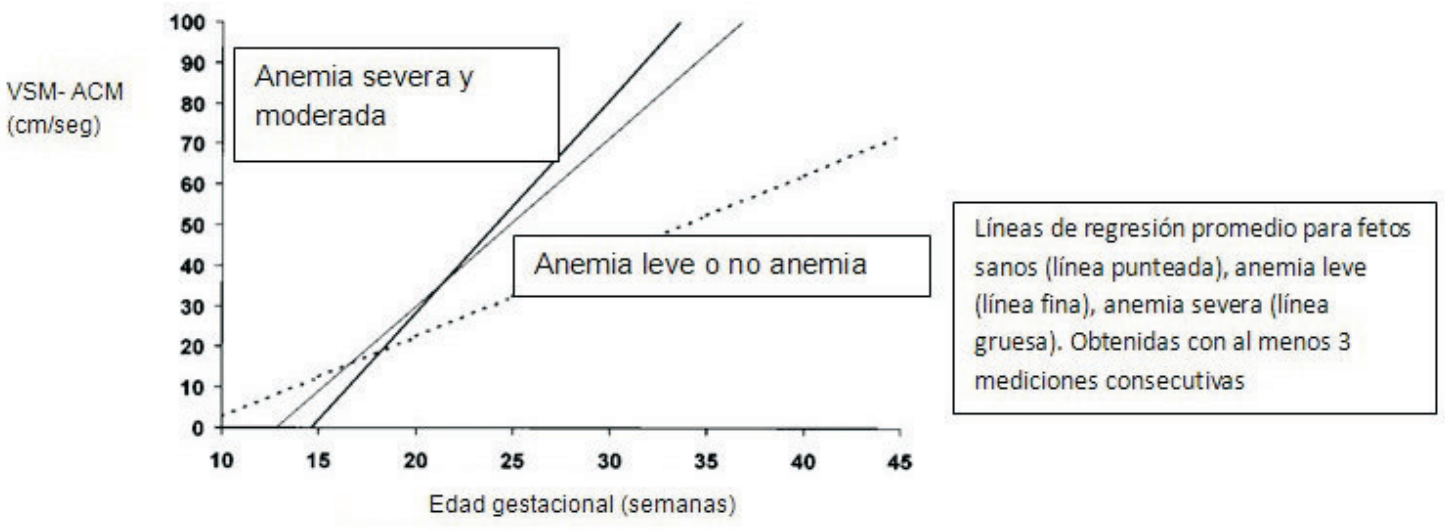

Figura 2. Tomado de Detti L, Mari G, Akiyama M, et al.Am J Obstet Gynecol. Longitudinal assessment of the middle cerebral artery peak systolic velocity in healthy fetuses and in fetuses at risk for anemia. 2002 Oct; 187(4):937-9.

ción de la VSM ACM por encima de 1,5 MoM, o ante la presencia de hidrops fetal. Esto deberá ser valorado en cada caso por el equipo tratante, y adaptado a la posibilidad de realizar de dicho procedimiento a nivel local ${ }^{(7)}$.

\section{Abordaje inmunohematológico}

\section{Estudios diagnósticos de aloinmunización materna y estudios en el recién nacido}

En la gestante:

1. Se realizará en la captación del embarazo estudio de grupo sanguíneo $\mathrm{ABO}$ y $\mathrm{Rh}(\mathrm{D})$ e investigación de anticuerpos irregulares clínicamente significativos que puedan afectar al feto o al recién nacido y para detectar anticuerpos que puedan causar problemas con el suministro de sangre compatible para la mujer y para el feto o recién nacido ${ }^{(4)}$.

2. En caso de investigación de anticuerpos irregulares positivos se identificará su especificidad y se determinara su asociación con EHFN ${ }^{(12)}$. Véase la tabla de especificidades con probabilidad de causar $\operatorname{EHFN}^{(13)}$.

3. En caso de madre $\mathrm{Rh} \mathrm{D}$ negativa si es posible se procede a estudio de genotipo fetal de antígeno D por PCR-RT en sangre materna partir de las 17 semanas para determinar el grupo sanguíneo fetal ${ }^{(14,15)}$.

4. En caso de identificación de otros anticuerpos con especificidad distinta al D asociado a EHFN podrá optarse por genotipificación para el antígeno involucrado por PCR-RT en muestra de sangre materna y fenotipo paterno en casos evaluados por el equipo asistencial si la técnica se encuentra disponible.
En gestantes $\mathrm{Rh} \mathrm{D}$ negativas, si no están inmunizadas contra el antígeno $\mathrm{D}$, se deberá realizar seguimiento inmunohematológico con screening para anticuerpos irregulares según la técnica disponible: a las 20, 24 y 28 semanas para la técnica en tubo y a las 20 y 28 semanas para la microtécnica en gel o similar sensibilidad ${ }^{4}$.

Es preciso determinar el fenotipo Rh D del RN mediante muestra de sangre del cordón umbilical. Si se trata de un RN Rh D positivo deberá administrarse inmunoglobulina anti $\mathrm{D}$ a la madre a las dosis indicadas.

En el recién nacido se determinará, en una muestra extraída del cordón umbilical, grupo sanguíneo ABO y $\mathrm{Rh}(\mathrm{D})$ y test de Coombs directo poliespecífico (TCD). En caso de resultado de TCD positivo se realizará elución e identificación de anticuerpos involucrados ${ }^{(16)}$.

\section{Abordaje neonatal}

Los efectos de la aloinmunización materna en el embarazo pueden determinar complicaciones de aparición fetal o puede presentarse a partir de la etapa exclusivamente neonatal. Este hecho determina que sea de capital importancia identificar los embarazos de riesgo y alertar al equipo neonatal.

El abordaje multidisciplinario de estos pacientes desde el inicio de la gestación es fundamental para mejorar los resultados perinatales.

El manejo neonatal inicialmente implica la realización de una historia clínica completa y un trabajo en conjunto con el equipo de medicina transfusional y obstetricia.

\section{Corticoides prenatales}

La administración de corticoides prenatales determina disminución de la incidencia de enfermedad de mem- 
Tabla 1. Especificidades de aloanticuerpos con probabilidad de causar EHFN.

\begin{tabular}{|c|c|c|c|c|c|c|c|}
\hline Anticuerpo & Sistema & Antígeno & Clase Ig & EHFN & $\begin{array}{c}\text { Gravedad } \\
\text { EHRN }\end{array}$ & $\begin{array}{c}\text { Seguimiento } \\
\text { ARO }\end{array}$ & Observación \\
\hline Anti-D & $\mathrm{Rh}$ & $\mathrm{D}$ & $\lg G$ & Sí & Severa & Sí & \\
\hline Anti-C & & C & $\lg G$ & Sí & Leve & Sí & \\
\hline Anti-c & & c & $\lg G$ & Sí & Leve-severa & Sí & \\
\hline Anti-E & & $E$ & $\lg G$ & Sí & Leve-moderada & Sí & \\
\hline Anti-e & & $\mathrm{e}$ & $\lg G$ & Sí & Leve & Sí & Usualmente raro \\
\hline Anti-K & KELL & K & $\lg G$ & Sí & Leve-severa & Sí & \\
\hline Anti-k & & k & $\lg G$ & Sí & Leve-severa & Sí & Usualmente raro \\
\hline Anti-Kpa & & Kpa & $\lg G$ & Sí & Leve-severa & Sí & \\
\hline Anti-Kpb & & $\mathrm{Kpb}$ & $\lg G$ & Sí & Leve-moderada & Sí & \\
\hline Anti-Jsa & & Jsa & $\lg G$ & Sí & Leve-severa & Sí & \\
\hline Anti-Jsb & & $\mathrm{Jsb}$ & $\lg G$ & Sí & Leve-severa & Sí & \\
\hline Anti-Fya & DUFFY & Fya & $\lg G$ & Sí & Leve-severa & Sí & EHFN severa: raro \\
\hline Anti-Fyb & & Fyb & $\lg G$ & Sí & Leve & Sí & Usualmente raro \\
\hline Anti- Jka & KIDD & Jka & $\lg G$ & Sí & Leve- moderada & Sí & Usualmente raro \\
\hline Anti-Jkb & & $\mathrm{Jkb}$ & $\lg G$ & Raro & Ninguna-leve & Sí & \\
\hline Anti-M & MNS & M & $\lg M / \lg G$ & Raro & Raro & $\lg G(\mathrm{Si}), \lg M(\mathrm{No})$ & IgG: casos raros \\
\hline Anti-N & & $\mathrm{N}$ & $\lg M / \lg G$ & Excepcional & Raro & $\lg G(\mathrm{Si}), \lg M(\mathrm{No})$ & IgG: casos raros \\
\hline Anti-S & & $S$ & $\lg G$ & Sí & Leve-severa & Sí & Usualmente raro \\
\hline Anti-s & & $s$ & $\lg G$ & Sí & Leve-severa & Sí & Usualmente raro \\
\hline Anti-Lea & LEWIS & Lea & $\lg M$ & No & Ninguna & No & \\
\hline Anti- Leb & & Leb & $\lg M$ & No & Ninguna & No & \\
\hline Anti-Lua & LUTHERAN & Lua & $\lg M$ & No & Ninguna & No & \\
\hline Anti-Lub & & Lub & $\lg G$ & Sí & Leve & Sí & \\
\hline Anti-P1 & $\mathrm{P}$ & P1 & $\lg M$ & No & Ninguna & No & \\
\hline Anti-PP1PK & & Pk & $\operatorname{lgM} / / g G$ & No/ Sí raro & Ninguna a severa & No & IgG muy raro \\
\hline Anti-I & I & I & $\lg M$ & No & ninguna & No & \\
\hline Anti-Di a & DIEGO & Di a & $\lg G$ & Sí & Leve a severa & Sí & \\
\hline Anti-Di b & & Dib & $\lg G$ & Sí & Leve & Sí & \\
\hline
\end{tabular}

Observación: por otras especificidades consultar literatura. Tomado de Marion E. Reid, Christine Lomas.Francis, Martin L. OlssonThe Blood Group Antigen. Facts Book. 2012. EHFN: enfermedad hemolítica feto neonatal; EHRN: enfermedad hemolítica del recién nacido; ARO: alto riesgo obstétrico .

brana hialina $(\mathrm{EMH})$ en el recién menor a 34 semanas y de dificultad respiratoria en neonatos menores de 39 semanas nacidos por cesárea sin trabajo de parto. A estos beneficios se les suma evidencia reciente que demuestra la disminución de aparición de ictericia y requerimiento de fototerapia en los RN mayores de 34 semanas. Es por estos motivos que es indiscutible la indicación de corti- coides prenatales en caso de que exista riesgo de parto de pretérmino ${ }^{(17)}$.

\section{Asistencia inicial}

Una de las complicaciones que se suman a la anemia fetal y el hidrops es el nacimiento prematuro, que agrega las complicaciones vinculadas a la prematurez. Para 


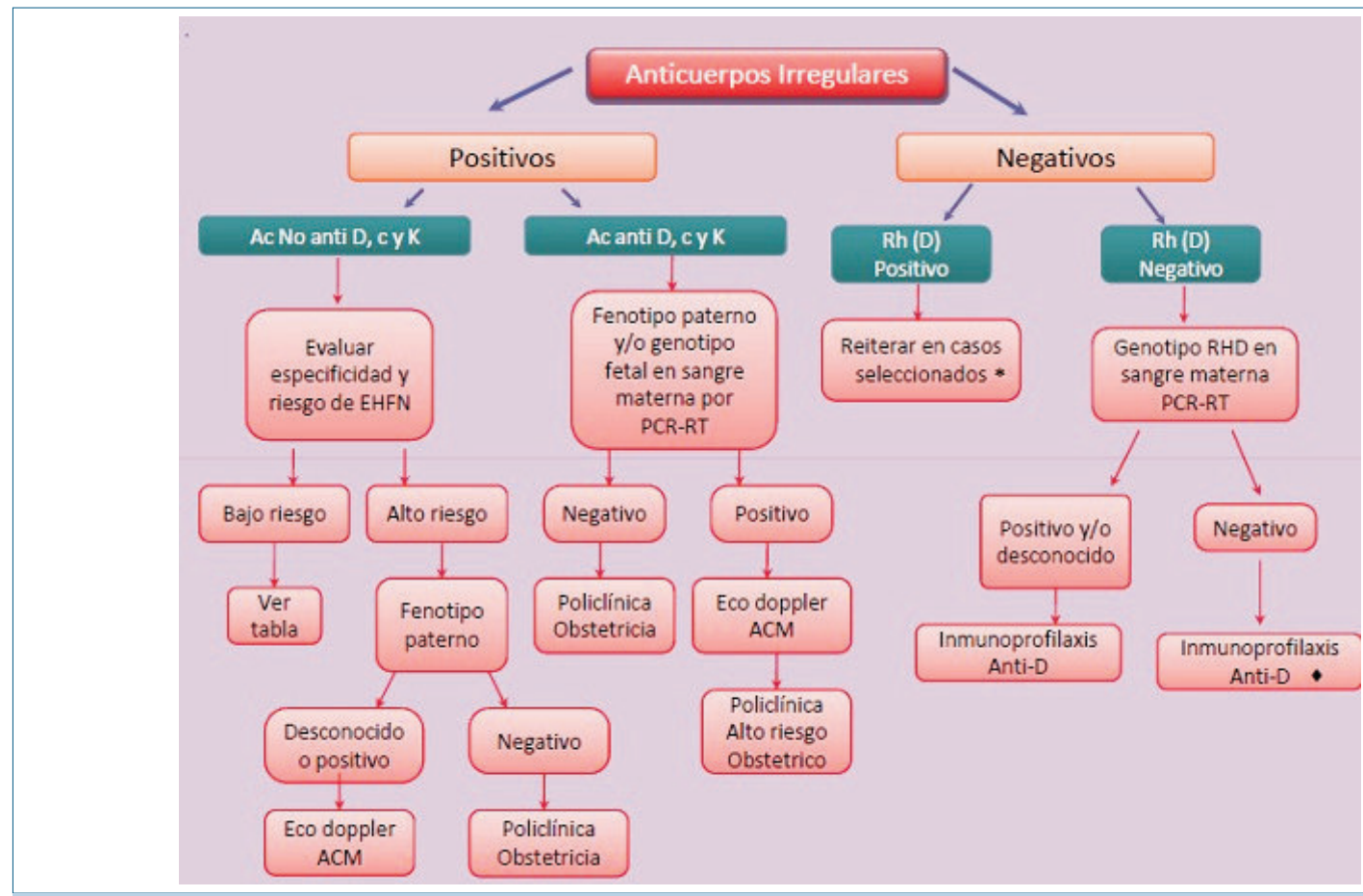

Figura 3. * Repetir en casos de transfusiones durante el embarazo, hidrops fetal o maniobras invasivas. - Se continuará la inmunoprofilaxis en gestantes con genotipo RHD negativo hasta validación de la técnica y modificación de la pauta ministerial vigente.

abordar esta situación es fundamental asegurar el nacimiento en un centro de tercer nivel. En esta situación clínica la asistencia inicial estará centrada en la estabilización del recién nacido y en los cuidados necesarios para lograr una adecuada adaptación a la vida extrauterina.

\section{Ligadura oportuna}

La ligadura oportuna de cordón es una conducta que ha demostrado beneficios en los recién nacidos de término y pretérmino ${ }^{(18)}$. Existe evidencia que demuestra beneficios en los recién nacidos que sufren anemia secundaria a aloinmunización materna ${ }^{(19)}$. En este grupo de pacientes la ligadura oportuna de cordón ha demostrado beneficios significativos en los niveles de hemoglobina desde el nacimiento, sin aumento en los niveles de hiperbilirrubinemia, y disminución en los requerimientos de transfusión de glóbulos rojos.

\section{Hemograma de cordón y grupo sanguíneo del RN urgente}

Se debe obtener en todo recién nacido grupo sanguíneo urgente y test de Coombs directo.

En los recién nacidos de alto riesgo se debe obtener hemograma de cordón y bilirrubina total ${ }^{(20)}$.

Abordar el tratamiento de la anemia y el tratamiento de la hiperbilirrubinemia en caso que corresponda.

\section{Recién nacido de alto riesgo}

- Maduración pulmonar fetal completa si corresponde.

- Ligadura oportuna.

- Grupo sanguíneo y TCD urgente.

- Hemograma y bilirrubina total de cordón.

- Recién nacido asintomático internación en sala de alojamiento madre hijo.

- Recién nacido sintomático tratamiento específico.

\section{Recién nacido de bajo riesgo}

- Ligadura oportuna.

- Grupo sanguíneo y TCD urgente.

- Recién nacido asintomático internación en sala de alojamiento madre hijo.

\section{Algoritmo de manejo en la gestante}

Véase la figura 3.

\section{Agradecimientos}

A los Dres. Pablo López y Mauricio Cabria que integran el Laboratorio de Patología Clínica Prof. Dra. Raquel Ballesté, Facultad de Medicina, Hospital de Clínicas, UdelaR. 


\section{Abstract}

Alloimmunization is the biological response to exposure to non-HLA antigens. Pregnancy, transfusion of blood components, solid organ and hematopoietic cell transplantation, as well as intravenous drug use expose patients to the development of anti-erythrocyte antibodies. When the latter are found, they must match diagnostic criteria to identify the potential association to hemolytic disease of the fetus and newborn (HDFN) and its timely referral to the high-risk obstetric risk polyclinic for due follow-up.

It is of the essence for erythrocyte alloimmunization diagnostic tests to be carried out by the immunohematology laboratories of the Hemotherapy and Transfusional Medicine services. To that end, we have prepared these guidelines with the purpose of providing a multidisciplinary protocol for the handling of maternal alloimmunization and alloimmunization of the newborn.

\section{Resumo}

A aloimunização é uma resposta biológica à exposição a antígenos não próprios. A gravidez, as transfusões de hemocomponentes, os transplantes de órgãos sólidos e células hematopoiéticas, bem como o uso de drogas intravenosas expõem os pacientes ao desenvolvimento de anticorpos antieritrocitários. O achado destes deve obedecer a critérios diagnósticos para identificar a doença e a probabilidade de estarem associados a doença hemolítica feto neonatal (DHPN) e seu encaminhamento oportuno para uma unidade de alto risco obstétrico para acompanhamento adequado.

É fundamental que os laboratórios de imuno-hematologia dos serviços de Hemoterapia e Medicina Transfusional se encarreguem dos estudos diagnósticos da aloimunização eritrocitária. Elaboramos este guia com o objetivo de estabelecer um protocolo multidisciplinar para o manejo de gestantes aloimunizadas e seus recém-nascidos.

\section{Bibliografía}

1. White J, Qureshi H, Massey E, Needs M, Byrne G, Daniels G, et al. Guideline for blood grouping and red cell antibody testing in pregnancy. Transfus Med 2016; 26(4):246-63. doi: 10.1111/tme.12299.

2. Laplane C, Carbonne B, d'Ercole C. Aloinmunización eritrocítica fetomaterna. EMC-Ginecología-Obstetricia 2018; 54(4):1-9. doi: 10.1016/S1283-081X(18)41443-9.

3. Cortey A, Brossard Y. Aspects pratiques. J Gynecol Obstet Biol Reprod 2006; 35(Suppl 1):123-30.

4. Uruguay. Ministerio de Salud Pública. Ordenanza $\mathrm{N}^{\circ}$ 99/011. Prevención de enfermedad hemolítica perinatal. 15 febrero 2011. Disponible en: https://www.gub.uy/ministerio-salud-publica/institucional/normativa/ordenan- za-n-99011-prevencion-enfermedad-hemolitica-perinatal

[Consulta: 11 diciembre 2020].

5. Sandler SG, Sathiyamoorthy S. Laboratory methods for Rh immunoprophylaxis: a review. Immunohematology 2010; 26(3):92-103.

6. Practice Bulletin No. 181: prevention of Rh D alloimmunization. Obstet Gynecol 2017; 130(2):e57-e70. doi: 10.1097/ AOG.0000000000002232.

7. Borrell A. Guías Clínicas Medicina Materno-Fetal: Isoinmunización. Barcelona: Fundación Medicina Fetal Barcelona, 2014. Disponible en: medicinafetalbarcelona/org/protocolos/es/patología-fetal/isoinminizacio-y-transfusion-intrauterina.html [Consulta: 4 enero 2021].

8. Mari G. Middle cerebral artery peak systolic velocity for the diagnosis of fetal anemia: the untold story. Ultrasound Obstet Gynecol 2005; 25(4):323-30. doi: 10.1002/uog. 1882.

9. Mari G, Deter RL, Carpenter RL, Rahman F, Zimmerman R, Moise KJ Jr, et al. Noninvasive diagnosis by Doppler ultrasonography of fetal anemia due to maternal red-cell alloimmunization. Collaborative Group for Doppler Assessment of the Blood Velocity in Anemic Fetuses. N Engl J Med 2000; 342(1):9-14.

10. Martinez-Portilla RJ, Lopez-Felix J, Hawkins-Villareal A, Villafan-Bernal JR, Paz Y Miño F, Figueras F, et al. Performance of fetal middle cerebral artery peak systolic velocity for prediction of anemia in untransfused and transfused fetuses: systematic review and meta-analysis. Ultrasound Obset Gynecol 2019; (54):722-31. doi: 10.1002/uog.20273.

11. Detti L, Mari G, Akiyama M, Cosmi E, Moise KJ Jr, Stefor $\mathbf{T}$, et al. Longitudinal assessment of the middle cerebral artery peak systolic velocity in healthy fetuses and in fetuses at risk for anemia. Am J Obstet Gynecol 2002; 187(4):937-9. doi: 10.1067/mob.2002.127310.

12. Webb J, Delaney M. Red blood cell alloimmunization in the pregnant patient. Transfus Med Rev 2018; 32(4):213-9. doi: 10.1016/j.tmrv.2018.07.002.

13. Reid ME, Lomas-Francis C, Olsson ML. The Blood Group Antigen FactsBook. 3rd ed. New York: Elsevier, 2012.

14. Sbarsi I, Isernia P, Montanari L, Badulli C, Martinetti M, Salvaneschi L. Implementing non-invasive RHD genotyping on cell-free foetal DNA from maternal plasma: the Pavia experience. Blood Transfus 2012; 10(1):34-8. doi: 10.2450/2011.0021-11.

15. Clausen FB, Barrett AN; Noninvasive Fetal RHD Genotyping EQA2017 Working Group. Noninvasive fetal RHD genotyping to guide targeted anti-D prophylaxis-an external quality assessment workshop. Vox Sang 2019; 114(4):386-93. doi: 10.1111/vox.12768.

16. Leger RM. La prueba de antiglobulina directa positiva y hemólisis de causa inmunólogica. In: American Association of Blood Banks. Manual Técnico. 17ª ed. Buenos Aires: Asociación Argentina de Hemoterapia e Inmunohematología, 2012:579-97.

17. Ree IMC, Smits-Wintjens VEHJ, van der Bom JG, van Klink JMM, Oepkes D, Lopriore E. Neonatal management 
and outcome in alloimmune hemolytic disease. Expert Rev Hematol 2017; 10(7):607-16. doi: 10.1080/1747408 6.2017 .1331124 .

18. Rabe H, Reynolds G, Diaz-Rossello J. A systematic review and meta-analysis of a brief delay in clamping the umbilical cord of preterm infants. Neonatology 2008; 93(2):138-44. doi: 10.1159/000108764.

19. Garabedian C, Rakza T, Drumez E, Poleszczuk M, Ghesquiere $\mathbf{L}$, Wibaut B, et al. Benefits of delayed cord clamping in red blood cell alloimmunization. Pediatrics 2016; 137(3):e20153236. doi: 10.1542/peds.2015-3236.

20. Calkins K, Roy D, Molchan L, Bradley L, Grogan T, Elashoff D, et al. Predictive value of cord blood bilirubin for hyperbilirubinemia in neonates at risk for maternal-fetal blood group incompatibility and hemolytic disease of the newborn. J Neonatal Perinatal Med 2015; 8(3):243-50. doi: 10.3233/NPM-15814111.

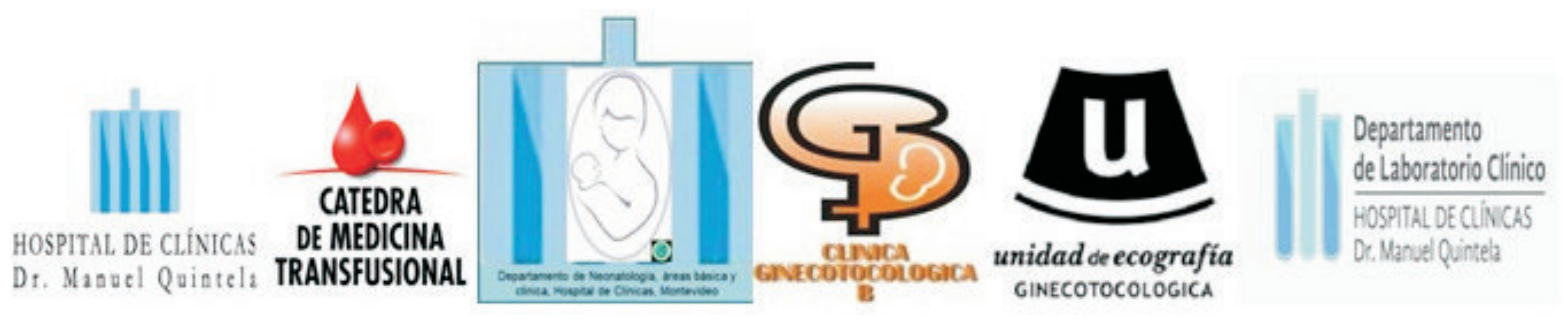

\section{Contribución de autores}

Todos los autores participaron en igual medida en la elaboración del artículo

Valentina Silveira, ORCID 0000-0002-9409-0742

Fernanda Blasina, ORCID 0000-0001-6697-5570

Gabriela Nevenka Rivas Alén, ORCID 0000-0001-5514-2143

Virginia Marcalain, ORCID 0000-0001-6226-1466

Juan Recouso, ORCID 0000-0002-5893-4178

Marcelo D Agostini, ORCID 0000-0002-5285-6594

Florencia Garat, ORCID 0000-0003-4232-9704

Jimena Bentos, ORCID 0000-0002-8356-683X

Cristina Cordano, ORCID 0000-0002-9453-0613

Grazzia Rey, ORCID 0000-0002-5970-6302

Valeria Correa, ORCID 0000-0001-7377-7580

Valeria Alonso, ORCID 0000-0002-6016-3640

Mariana Sauleda, ORCID 0000-0002-1308-320X

Ismael Rodríguez, ORCID 0000-0002-3361-7117

Luis Miguel Gómez, ORCID 0000-0002-4770-1571 